\title{
THE TREATMENT OF VENOUS THROMBOSIS
}

\author{
By R. S. MurLeY, M.S., F.R.C.S. \\ Royal Northern Hospital
}

The introduction of the anticoagulant drugs promoted widespread interest in venous thrombosis and pulmonary embolism, and a considerable literature has accumulated in the last decade or so. Few methods of treatment are as good as they at first seem to be and certainly anticoagulant therapy is no exception to this. Quite apart from over-enthusiastic reports on the value of the anticoagulant drugs, many misleading claims have been made for other forms of treatment such as paravertebral block and vein ligation. It is certainly more easy to assess the value of these various methods of treatment at the present time than was the case a few years ago. The purpose of this article is to discuss the prevention and treatment of venous thrombosis without any detailed consideration of aetiology and pathology.

\section{Incidence}

Relevant to this discussion is the actual incidence of thrombosis. The recorded incidence can be increased or decreased at least threefold by different standards of diagnosis, and every individual or institution with an interest in thrombosis has encountered difficulties from this source. A seemingly trivial sign may be succeeded by extensive thrombosis and an apparently slight thrombosis can be followed by serious incapacity many years later. The assessment of the immediate results in cases of astutely diagnosed thrombosis may justify the criticism that, say, two out of three cases must be ' unnecessarily' treated in order to benefit the third. But the long-term assessment of such cases may show that post-thrombotic sequelae are materially less common in the treated group, and a good deal more information is needed about this aspect of the problem. These factors are but a few amongst many which are difficult to assess fairly and fully. Added to these considerations are the many problems posed by different sampling of material; by widely varying systems of treatment and, finally, by the difficulty of assessing objectively the actual results achieved.

\section{Prevention}

Prevention is a worthy objective but it is neces- sary to have a clear idea of the pathogenesis of thrombosis and of what one is trying to prevent. It is customary to list venous stasis, trauma and blood changes as the basic factors in thrombosis, but the detailed research which has gone into these aspects of aetiology has not yielded any effective or practicable method of prophylaxis suitable for general use. Different authorities underline this or that aspect of aetiology, but it is generally unwise to emphasise one aspect to the exclusion of others.

Venous Stasis. The type of patient in whom venous stasis, and possibly vein trauma, is of importance is well exemplified by cases of thrombosis and pulmonary embolism occurring in those who spent the night sitting on deck chairs in airraid shelters. A number of cases of 'idiopathic' thrombosis are attributable to prolonged sitting in trains, cars or aircraft (Homans 1954), or to dozing for long periods on beach chairs.

Early Ambulation. Relevant to this matter of venous stasis is the question of early rising and ambulation following operations and childbirth. Other things being equal, a patient who returns rapidly to normal activity is less likely to develop thrombosis than one who lies fallow in bed. Some have claimed a striking reduction in venous thrombosis following early ambulation, but the consensus of opinion would suggest that rising on the first or second day after an operation does not greatly reduce thrombosis, and that the incidence of fatal embolism is unchanged (Blodgett and Beattie, 1946; McCann, 1950). There are, of course, considerable differences in the interpretation of such terms as early rising and ambulation and it can be very difficult to ascertain the exact practice in another hospital. Moreover, early rising may be anything but beneficial in some cases. For example, an old, unwell or unwilling patient, huddled up in an armchair with bent knees and chilled extremities, must surely be at greater risk for thrombosis than if he is snugly comfortable and active in bed with the foot of the bed raised six inches. The almost indecent desire of some surgeons to get patients early from their beds has sometimes led to the neglect of active movements in the bed. The report from the Lahey Clinic that a hospital with 
nursing staff trained to encourage ' bicycle' exercises had one-third the incidence of thrombosis in another hospital where this was not the practice is a salutary reminder on this point (Evans and Buller, 1947). Whilst it is a good rule for the clinician constantly to ask himself " why am I keeping this patient in bed?', it is important to avoid making a fetish of early rising.

Other Measures. Without discussing these in detail mention should be made of the importance of avoiding impairment of respiration and circulation by awkward positioning of the patient, and also by tight bandages or undue pressure on the calves. Comfortable support of the legs by firm bandages or elastic stockings during an illness is of positive value, especially in a patient who has had previous thrombosis. It has been shown that support of this kind appreciably increases the speed of the venous return (Stanton et al., 1949).

Blood Changes. Despite the vast literature on this subject knowledge of the blood changes underlying thrombosis is still incomplete. The peculiar predisposition of certain patients to thrombosis, such as those with cancer, is recognised but not understood. A distinct tendency to thrombosis and embolism following blood transfusion has also been observed but defies explanation. Were it possible to influence such changes without rendering the blood incoagulable an important advance would have been achieved.

Prophylactic Anticoagulant Therapy. A number of large-scale trials of routine anticoagulant therapy following surgery have been made. The use of heparin in surgical cases is fraught with serious risk if this drug is given shortly after operation, and even if it be started two or three days later the risks of bleeding are still high (Jorpes, 1946; Murray, 1947). Prophylactic heparin therapy, though occasionally justifiable in carefully selected surgical and obstetric cases, has but limited value and similar arguments apply to dicoumarol (Barker et al., I945) and related drugs. To avoid the risk of bleeding various attempts have been made to effect a more conservative depression of the prothrombin level to not less than 40 per cent. (Wise et al., I949), but there are still real risks of bleeding in non-medical cases. Any possible advantage of this last practice must be outweighed by the prodigious clinical and laboratory effort needed to maintain it. The introduction of new and shorter-acting oral anticoagulant drugs during the last few years has not materially altered this position. In summary then, it is only justifiable to give anticoagulants prophylactically in surgery and obstetrics when: (I) the patient has had previous serious thrombosis or embolism; (2) the risks of bleeding do not seem high, and (3) there is good reason to supposet that the advantages will outweigh the fully calculated risks. Any operation involving wides dissection of tissue planes, such as radical mas $\frac{\widehat{D}}{\alpha}$ tectomy or excision of the rectum, or in which $x$ raw surface is left, as in prostatectomy, must: rarely justify prophylactic treatment. In medical? cases there is not the need for so much caution and yet the indications for prophylactic therapy are limited. Whilst the writer is hardly qualified to comment on the use of anticoagulants in such cases it would seem apt to refer to their use in cases of coronary occlusion. In these patients it can becontended that treatment is given with the objectof preventing thrombosis in the coronary vessels $\vec{\omega}$ and also in the peripheral veins. Opponents of such treatment may be justified in doubting itso achievement of the first objective, but there can be no doubt of its value in reducing peripheral thrombosis and pulmonary embolism. In generale it is easier for the physician to judge the merits of prophylactic treatment since his patients are not $\vec{\omega}$ exposed to the additional hazard of bleeding from $\mathrm{w}_{\mathrm{O}}^{\mathrm{N}}$ an operation site.

\section{Treatment of Established Thrombosis}

Thrombosis affecting the deep veins of the legs $\frac{\text { }}{\text { क }}$ is certainly detected earlier nowadays than in the past. Whereas this offers opportunity for mofec effective treatment it also sets the problem as $0^{\circ}$ which cases really need treatment. If treatmento carried no risks then there would be little hesita-s tion in treating every patient at the earliest possibleō moment. However, a brisk or, worse, a fatal bleedő in one of these cases quickly sets the clinician on the defensive and, once on the defensive, he will $\overrightarrow{0}$ tend to limit treatment to the most obvious and 3 advanced cases. Each clinician has to learn to steer his way between the extremes of undue? conservatism on the one hand and of unnecessarilyo officious treatment on the other.

Early Diagnosis. A prerequisite of early diag-产 nosis is a sense of awareness of this condition. Aching or stiffness in the legs sometimes precedes more obvious signs by several days. Examination of the legs with hips and knees semi-flexed and윽 feet comfortably on the bed may reveal localized $>$ tenderness and increased girth and consistency of the calf muscles. The normal relaxed calf muscle N shakes like a jelly, but one related to an underlying thrombosis feels like a stiff blancmange. TheO soleus, gastrocnemius and, occasionally; the thigh $\omega$ muscles are the most likely site of physical signs. That well-localized muscle tenderness can be을 exactly related to a thrombosed intramuscular vein $\$$ is shown by the specimen illustrated in Fig. I. +

Subcutaneous oedema of localized distribution $\frac{0}{-}$ is sometimes related to a thrombosed superficial 


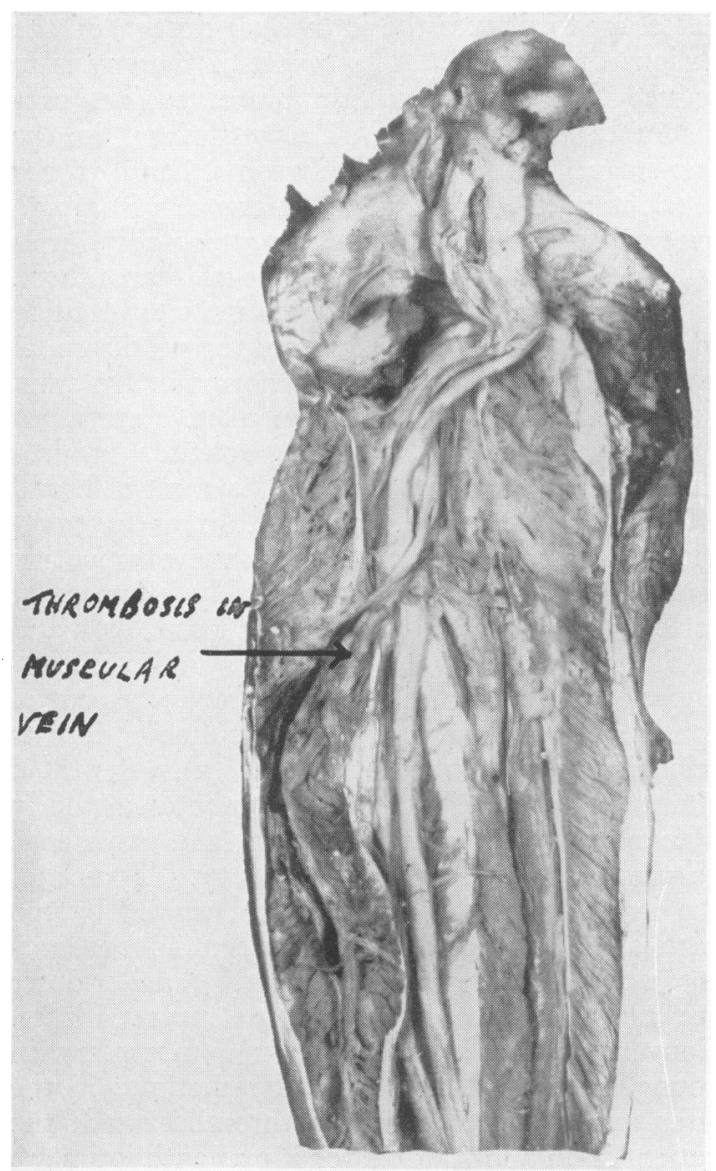

Fig. 1.-Specimen of right calf from a man aged 79 . The muscles have been split in the midline and then opened out to display the main vessels. The only thrombosis is in a muscular vein situated between soleus and medial head of gastrocnemius. This corresponded with the exact site of tenderness during life. Heparin was given from the third day after resection of the rectum until death from heart failure nine days later.

vessel. More diffuse oedema of foot and ankle usually connotes deep vein involvement up to popliteal level. Gross oedema is a late feature and it should usually be possible to detect thrombosis before this stage.

Despite all that has been said about early diagnosis fatal embolism is sometimes the first sign of trouble. Such occurrences, especially in young patients, may be real tragedies and it is regrettable that we still fail to predict and prevent them. Non-fatal emboli, even today, are surprisingly often missed or misdiagnosed, and such emboli, besides being numerically more frequent, are clinically more important than the massive ones since their prompt recognition may prevent an associated leg vein thrombosis from being missed.

Diagnostic Tests. Much effort has been made to devise a reliable laboratory test for early thrombosis. Though a number of observers have recorded shortening of the clotting time at the onset of thrombosis, this is rarely a feature prior to the onset of trouble. The bulk of experience suggests that daily clotting times (Bergquist, I945), heparin response tests (de Takats, I943), estimation of Fibrinogen B (Cummine and Lyons, 1948), thrombin effect (Bergquist, 1945), platelet counts and adhesiveness (Payling Wright, I94I and 1942), plasma prothrombin (Shapiro et al., 1942), are of no practical value in predicting thrombosis. Many of these tests have been reviewed previously (Murley, 1950) and more recent publications seem to confirm that none of them is reliable.

Which Signs fustify Therapy ? It is reasonable to ask which cases, if any, can be left to take care of themselves and which demand definitive treatment. Whereas some signs should merely alert the clinician, others may be regarded as absolute indications for treatment. An alerting sign may constitute a good reason for starting anticoagulants in a patient who has had previous thrombosis, whereas an absolute indication may not justify therapy in certain cases. At risk of appearing somewhat dogmatic these two groups of signs are set out in Table $\mathrm{I}$, together with certain ' loading ' and 'cautionary' factors. Suspicious pyrexia, the first of the alerting signs, may be defined as an otherwise unexplained pyrexia in a patient who is at risk for thrombosis. Even such a sign as this occurring alone in a patient who has had previous trouble may sometimes justify treatment. In respect of the absolute indications set out in Table $\mathrm{r}$, it is important to consider carefully the hazards before embarking on treatment.

\section{TABLE I}

Indications for Treatment of Thrombosis

AlerTING SignS (Relative Indications):

Suspicious pyrexia; or

Aching leg muscles; or

Tender muscles.

Loading Factors:

Previous thrombosis.

Disease with special risk of thrombosis. Absolute Signs:

Turgid and tense muscles.

Oedema.

Pulmonary embolism.

Spreading superficial thrombosis in a recumbent patient.

Two or more of the relative indications.

Cautionary Factors:

Cases with risk of bleeding.

Cases with extensive infarction of lung and risk of haemothorax, etc. 


\section{The Choice of Drugs}

When, as is commonly the case, an immediate effect is required heparin is the drug of choice. Swedish authorities suggested that four intravenous injections at four-hourly intervals by day (with none between 8 p.m. and 8 a.m.) would suffice; but it is difficult to accept a regime which implies no anticoagulant cover for about eight hours of the night while the patient is immobile. Six-hourly intravenous injections have been used by many but the tendency now is to give heparin four-hourly throughout the whole 24 hours. The use of indwelling needles with rubber diaphragms or of polythene tubing has greatly facilitated this regime.

Following the introduction of heparin in Pitkin's menstruum for subcutaneous injection a number of delayed-action preparations have been made for intramuscular use. Owing to the variable rate of absorption of the drug, and the risk of summation of dosage, these long-acting preparations have not achieved wide popularity. However, for the patient who has to remain on heparin for some time they do sometimes fulfil a very definite need. Continuation of heparin beyond the first 48 hours or so of treatment is only indicated when immediate neutralization of the anticoagulant effect must be possible (e.g. cases with serious risk of haemorrhage), and when there are not adequate laboratory facilities for the control of prothrombin level.

In the ordinary way prolonged treatment is best effected with one of the slow-acting synthetic drugs of which several are now available. Most clinicians prefer one of the shorter-acting drugs such as bis-3-3'-(4 oxycoumarinyl) ethyl acetate ${ }^{\star}$ or phenylindanedione rather than the more persistent dicoumarol. It is unprofitable to argue the relative merits of these drugs since their safety factors will depend upon both the clinician's and pathologist's experience in their use.

Heparin. In an average adult 10,000 to 12,500 units intravenously is the initial dose followed by I0,000 units four hourly. The value of routine estimations of the clotting time during treatment is arguable, but if such tests are used, they should be done at a regular time interval after injection. In the event of bleeding, ro $\mathrm{ml}$. of I per cent. protamine sulphate solution will neutralize 10,000 units of heparin in a few minutes. With sloweracting intramuscular heparin a second dose of protamine may be needed four hours later to counteract further heparin released from the muscle depot.

The Dicoumarol Group of Drugs. It is un-

*Also called 'Tromexan', B.O.E.A. or ethylbiscoumacetate. necessary to discuss the individual dosage of the various drugs used. The object of therapy is tथ reduce the plasma prothrombin level (i.e. pros thrombin plus Factor VII as estimated in the one-stage Quick test) to between 15 and 30 per. cent. of normal. There is difference of opinio $\overrightarrow{\overline{7}}$ over this question of optimum prothrombin levels and some aim at much lower level than others In the absence of a recent operation site bleedin rarely occurs spontaneously until the prothrombin level is below ro per cent. of normal. No valif evidence is available about the relative merits of different levels and, in average hands, a proe $\vec{e}$ thrombin of 20 to 30 per cent. is most safe and effective. The really important thing in treat ment is to depress the prothrombin level smoothly and steadily. This is most readily effected by selecting a suitable dose of the chosen drug and avoiding hasty changes of dosage. With phenylindanedione it is striking how effectively controक can be established providing a suitable dose is selected and adhered to (Fig. 2). Repeated alteration of dosage generally connotes a poorls planned and controlled treatment, and experience ensures more even control of therapy. Typical of the irregular prothrombin control caused by tog high an initial dose and subsequent inconstanc $\bar{y}$ is the case chart depicted in Fig. 3. Smaller desess are needed in aged, ill and decrepit patients Conversely, more anticoagulant is necessaryōim young and fit individuals, and sometimes in the later stages of recovery from thrombosis. If the patient is on a low fat diet or if oral antibiotics are being used (with depression of Vitamin K synthes 8 in the gut) there may be hyper-reaction to the coumarin drugs (Payling Wright and Hayder I955). It is wise to keep a daily specimen of urine for examination. Red blood cells are common found in the urine but gross blood may be the firsi sign of overdosage. Phenylindanedione some times causes orange or red discoloration in ain alkaline urine which should not be mistaken for blood. Estimation of plasma prothrombin should if possible, be done at the same time each day, and when heparin is being given too the sample should be collected at least four hours after the last injection.

In the event of haemorrhage necessitating arrest of treatment IO-I5 mg. Vitamin KI should be given intravenously.

Contraindications to Anticoagulant Therap Patients with severe liver disease or renal insuf ficiency; those with known peptic ulcer, and thos in the early post-operative period (especially aftes the potentially more haemorrhagic proceduresy are risky subjects for anticoagulant treatmene, especially with the coumarin drugs. Salicylates 


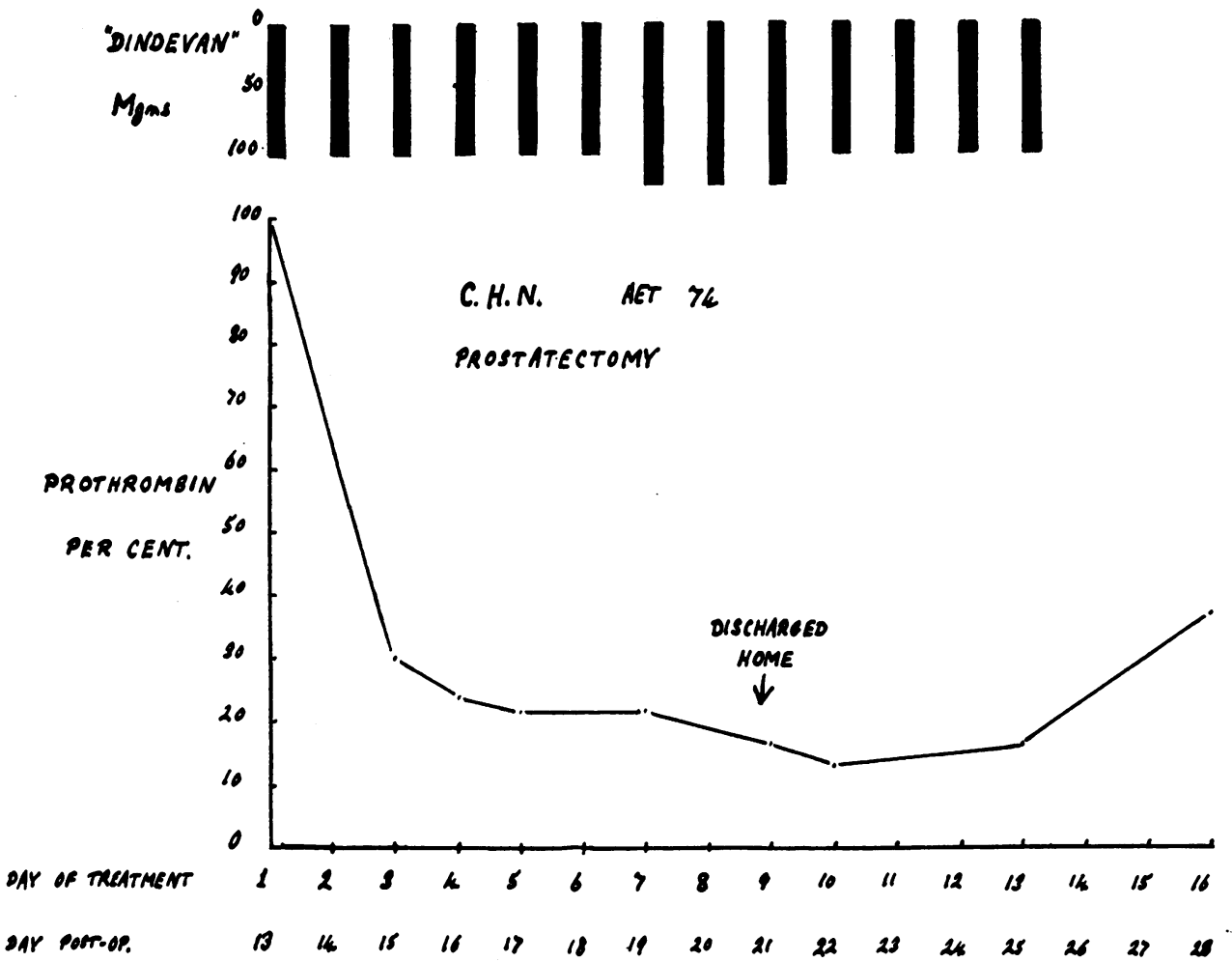

Fig. 2.-Post-operative thrombosis well controlled by phenylindanedione.

Note steady dosage throughout treatment.

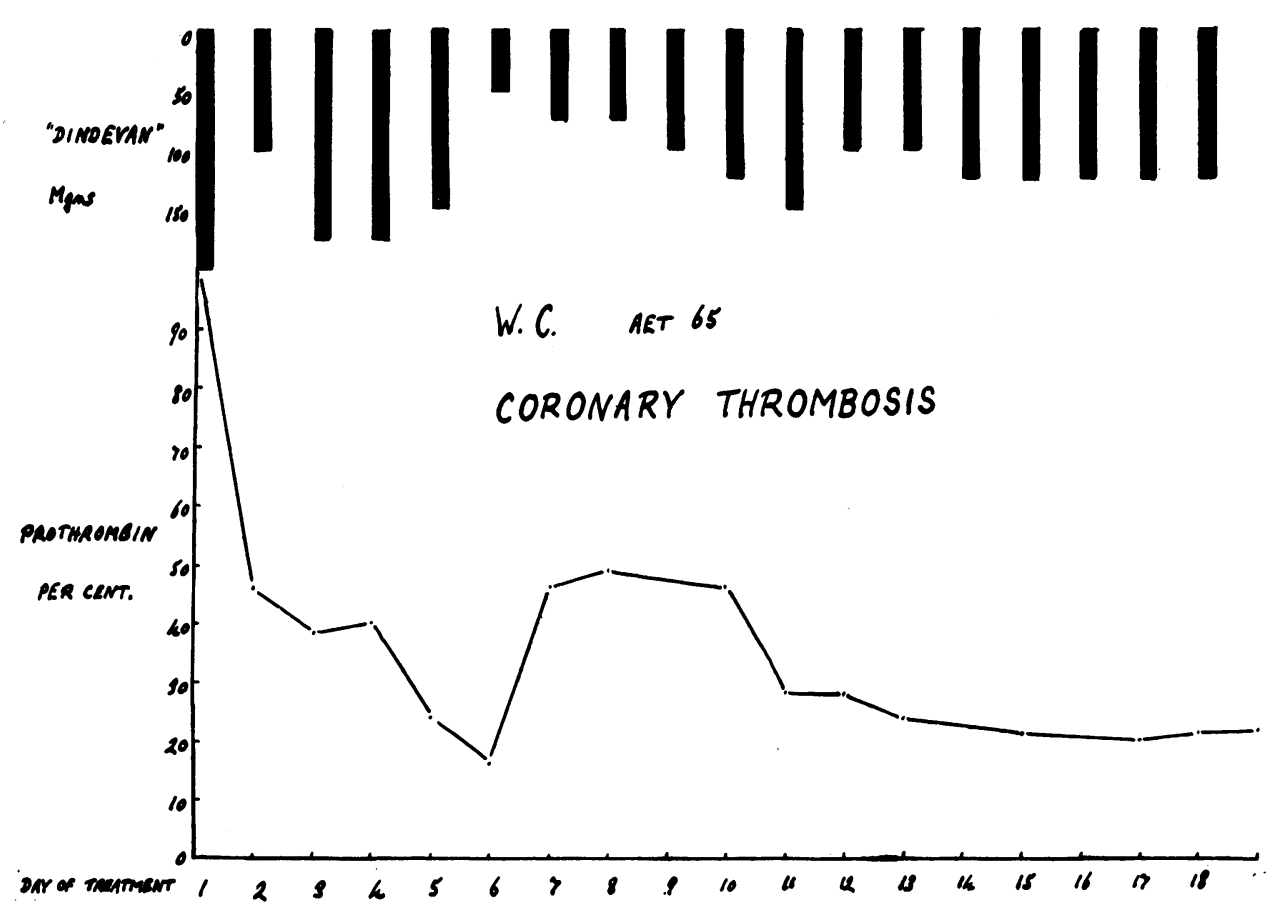

Fig. 3.-Coronary Thrombosis. Irrregular control during first ten days due to poor selection of phenylindanedione dosage. 
caffeine and other purine derivatives lower the plasma prothrombin and should be avoided or used carefully. The menstrual blood loss is rarely excessive during oral anticoagulant therapy, but in the early puerperium it is safer to use heparin. If intramuscular injection of other drugs is necessary during treatment, firm pressure should be maintained at the injection site for a few minutes to discourage haematoma formation.

The Period of Treatment. It is most difficult to give an authoritative answer to the question as to how long treatment should be given. Certainly it should continue until all signs of active trouble are gone; pyrexia settled, and the patient fully mobile. On the average this will mean full dosage for a period of about two weeks in early peripheral vein thrombosis and proportionately longer in other cases. Now that better long-acting anticoagulants are available it is sometimes a good idea to discharge the patient home to attend for checkup at the laboratory twice a week. In these circumstances treatment can continue for three or four weeks and even for very much longer. At the end of the course of treatment it is probably wise to tail-off dosage for the sudden withdrawal of anticoagulant may be followed by reactivation of thrombosis. By gradually reducing the dose during the last week and avoiding too short a course of treatment it is probable that there is less chance of recurrence.

When Should the Patient Get Up? The patient should remain in bed so long as his general condition compels this, and if he is at risk for embolism or has a painful leg. In untreated cases fatal embolism quite often occurs when the patient gets up, and embolism may also occur at this time in a patient who is inadequately treated or who gets up too soon. Such pathological evidence as is available would suggest that a ' waving' thrombus in a peripheral vein becomes quite well organized within a few days (Hadfield, I950). For these various reasons it would seem logical to keep the patient in bed for from four to seven days after adequate anticoagulant control has been established, unless there are still contraindications to rising.

Adjuvant Measures. Elevation of the foot of the bed by 4 in. or 6 in. assists the venous return and this is of especial value at night when muscular activity is slight.

The value of breathing and limb exercises has already been emphasised in connection with prophylaxis.

Support of the legs with firm crepe bandages or elastic stockings should continue for a month after completion of treatment. Patients with residual oedema of a leg may require mo prolonged or even permanent support.

\section{Other Methods of Treatment}

Paravertebral Block. Although paravertebrâ block has enjoyed a vogue in certain quarte (Leriche, I934; Ochsner, 1940), it has not achieved much popularity. On theoretical grounds it would appear to be indicated in those uncommonf cases associated with well-marked vascular spasn 8 but apart from this it would not seem so logical as anticoagulant therapy. When, however, the clinis cian is skilled in paravertebral block, and when anticoagulant therapy is considered hazardous there would seem to be a good case for the alternative method of treatment. It should nev be combined with anticoagulants for fear of. retroperitoneal haemorrhage of which a numbexp of instances have been recorded.

Stellate ganglion block has been recommendee in the treatment of severe pulmonary embolisna. and it has been claimed that there is dramatys relief of symptoms (Bageant and Rapee, 1947). It is difficult to assess the merits of this claim and doubtful whether it has found any wide acceptancou

Vein Ligation. Ligation of the deep veins of the legs was briskly advocated and extensigetb practised in Boston and certain other centres a years ago. The published figures certainly do support the argument for superficial femoral ligation and there is no doubt that large numbers of veins were needlessly tied (Zimmerman et a I949). It is significant that at the Massachusetes General Hospital, where so many superficiaif femoral veins were tied in the 1940's, the operatio is infrequently done today. Nevertheless, there can be no doubt that ligation of the deep veins at higher level can prevent pulmonary embolism. Ligation of the lower part of the inferior vena cav affords the nearest thing to complete protection: it may be justified when pulmonary embolism has occurred; when further embolism is greatlis feared, and when anticoagulants are contraindis cated. Although the operation is a technicall $\$$ simple procedure through a right extraperitonea approach at the level of the umbilicus it should nơ be lightly undertaken. The ultimate morbidit: has been variously reported, but personal experi ence would suggest that this depends on the pres existent stage of thrombosis and the venous anatomy of the individual patient.

There is a case for bilateral ligation of the common femoral veins in cardiac patients whō suffer repeated embolism but are not fit for a tie at higher level, and in whom prolonged anticoagulanp therapy is not desirable. For example, if there already extensive pulmonary infarction, ant 
coagulants can cause marked bleeding into the lung and pleura.

\section{Treatment of Pulmonary Embolism}

Most of the points in treatment of pulmonary embolism have been dealt with already. When embolism occurs it is generally right to start heparin treatment immediately, whilst the injection of morphine, gr. $\frac{1}{4}$ and atropine gr. $1 / 75$ is also of value. Intravenous injection of papaverine sulphate (with the object of producing pulmonary vasodilatation) was formerly advocated but is almost certainly of no more value in dilating the pulmonary than the systemic arteries when given in this way (Kinmonth, 1952).

The need for cautious use of the anticoagulants in cases of extensive pulmonary infarction has already been emphasised. In such cases vein ligation may be the safest method of preventing further embolism. In this connection it should be noted that certain Australian authorities (Cummine and Lyons, 1948; Dew, 1953), have contended that pulmonary artery thrombosis is more common than embolism, and they have advanced various reports from the older literature in support of this view. However, it was rare for the leg veins to be completely dissected at the autopsies from which these reports were derived and, in the absence of such complete examination, it would be rash to deny the occurrence of embolism. That massive thrombosis of the pulmonary arteries does occur, is well-established. It is significant that in at least one of the more recent reports on pulmonary artery thrombosis (Keating et al., 1953), the leg veins are described as rarely free from thrombosis.

\section{Conclusions}

With intelligent use of the various measures now available it is certainly possible to do much more for the patient with thrombosis than was possible a few years ago. Even in the more difficult cases of thrombosis the clinician who has a good laboratory to help him should be able to treat his cases with relative safety. Prevention and treatment of thrombosis is still difficult in many cases, especially in those patients who may bleed from an operation site during anticoagulant therapy. A great deal of research is needed to clarify many obscure aspects of aetiology and pathogenesis without which truly rational therapy will never be possible. The author is conscious that many questions are left unanswered in this review, and that scientific information is sadly lacking on many aspects of thrombosis.

\section{Acknowledgment}

I am indebted to the editor of Annals of the Royal College of Surgeons of England ior permission to reproduce Fig. I.

\section{BIBLIOGRAPHY}

BAGEANT, W. E. and RAPEE, L. A. (1947), Anesthesiology, 8, 5 co. BARKER, N. W., CROMER, H. E., HORN, M. and WAUGH, J. M.'(I945), Surgery, 17, 207.

BERGQUIST, G. (1945), Acta Chir. Scand., 92, suppl. ror. BLODGETT,' J. B. and BEATTIE, E. J.' (1946), Surg. Gynec. Obstet., 82, 485 .

CRANE, C. (1952), New England F. Med., 246, 529.

CUMMINE, H. and LYONS, R. N. (1948), Brit. F. Surg., 35, 337. de TAKATS, G. (1943), Surg. Gynec. Obstet., 77, 31 .

DEW, H. (1953), Ann. Roy. Coll. Surg. Engl., 13, 1.

EVANS, J. A. and BOLLER, R. J. (1947), New England F. Med., 236, 392.

GREIG, G. W. V. (1949), Brit. med. F., ii, 845.

HADFIELD, G. (1950), Ann. Roy. Coll. Surg. Engl., 6, 219.

HOMANS, J. (1954), New England $\mathcal{F}$. Med., 250, 148.

JORPES, J. E. (1946), 'Heparin in the Treatment of 'Thrombosis,' Oxford University Press, London.

KEATING, D. R., BURKEY, J. N., HELLERSTEIN, H. K. and FEIL, H. (1953), Amer. Ұ. Roentgenol., 69, 208.

KINMONTH, J. B. (1952), Brit. med. F., i, 59.

LERICHE, R. and KUNLIN, J. (1934), Presse méd., 42, $148 \mathrm{I}$.

McCANN, J. C. (1950), New Eng. F. Med. 242, 203.

MURLEY, R. S. (1950), Ann. Roy. Coll. Surg. Engl., 6, 283.

MURRAY, G. (1947), Amer. F. Med., 3, 468 .

OCHSNER, A. and De BAKEY, M. (I940), f. Amer. med. Ass.

SHAPIRO, S., SHERWIN, B. and GORDIMER, M. (I942), Ann. Surg., I16, 175.

STANTON, J. R., FREIS, E. D. and WILKINS, R. W. (I949);

W. Clin. Invest., 28, 553 . Surg. Gynec. Obstet., $88,486$.

WRIGHT, H. P. (194I), F. Path. Bact., 53, 255.

WRIGHT, H: P. (1942), Ibid., 54, 46I.

WRIGHT, H. P. and HAYDEN. M. (1955), F. Clin. Path., 8, 05.

ZIMMERMAN, L. M., MILLER, D. and MARSHALL, A. N. (1949), Surg. Gynec. Obstet., 88, 373.

\section{RUTHIN CASTLE, NORTH WALES}

A Clinic for the diagnosis and treatment of Internal Diseases (except Mental or Infectious Diseases). The Clinic is provided with a staff of doctors, technicians and nurses.

The surroundings are beautiful. The climate is mild. There is central heating throughout. The annual rainfall is $\mathbf{3 0 . 5}$ inches, that is, less than the average for England.

The fees are inclusive and vary according to the room occupied.

For particulars apply to THE SECRETARY, Ruthin Castle, North Wales. 